Part of Journal of Research of the National Bureau of Standards, Volume 34, May 1945

\title{
INTRINSIC VISCOSITIES AND OSMOTIC MOLECULAR WEIGHTS OF CELLULOSE ACETATE FRACTIONS
}

\author{
By Arnold M. Sookne and Milton Harris ${ }^{1}$
}

\section{ABSTRACT}

The intrinsic viscosities and osmotically estimated number-average molecular weights of a series of cellulose acetate fractions have been measured. It was found that within the range of chain lengths investigated (number-average molecular weight, $\bar{M}_{n}$, up to 130,000 ) the number-average molecular weights are proportional to the intrinsic viscosities in acetone solutions, in agreement with Staudinger's rule and the results of Kraemer. An estimate is provided of the relative homogeneity with respect to molecular size of the fractions and the starting material from which they were prepared.

\section{CONTENTS}

I. Introduction

II. Methods

1. Viscosity measurements _. _. . .

2. Osmotic-pressure measurements . . $\ldots \ldots \ldots \ldots$.

III. Results and discussion

IV. References _...

\section{INTRODUCTION}

According to Staudinger's rule, the molecular weight, $M$, of a linear

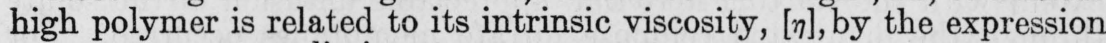
$[\eta]=K M$, where $[\eta]=\operatorname{limit}_{c \rightarrow 0}\left(\eta_{s p} / c\right), K$ is a constant, and $c$ the concentration in grams per $100 \mathrm{ml}$ of solution [1]. ${ }^{2}$ The validity of this relationship has often been questioned, and it has recently been demonstrated that several unbranched polymers do not conform to this rule but rather to the more general relationship $[\eta]=K M^{a}$, where $a$ is a constant with a value between 0.5 and $2[2,3]$.

Some time ago a series of cellulose acetate fractions was prepared in this laboratory in connection with a study of the mechanical properties of this material [4]. ${ }^{3}$ The intrinsic viscosities and the osmotically estimated molecular weights of these fractions and of the starting material have now been determined in acetone solutions. This

\footnotetext{
1 Research Associates at the National Bureau of Standards, representing the Textile Foundation.

2 Figures in brackets indicate literature references at the end of this paper.

${ }^{3}$ The starting material from which the fractions were prepared had an acetyl content of 38.6 percent, an ash of 0.06 percent, a melting point of $250^{\circ} \mathrm{C}$ and a char point of $301^{\circ} \mathrm{C}$.
} 
paper, which presents the results of these measurements, shows that for this type of acetate and within the range of chain lengths investigated, the system cellulose acetate in acetone does conform to Staudinger's rule; i. e., for this system the constant $a$ has the value unity in the relationship cited above.

\section{METHODS}

\section{VISCOSITY MEASUREMENTS}

The viscosity measurements were made in an Ostwald viscometer at $25^{\circ} \pm 0.03^{\circ} \mathrm{C}$. As the time of efflux of the acetone was approximately only 30 seconds, kinetic-energy corrections were applied ${ }^{4}$ [5]. These were determined by calibrating the viscometer with oils of known viscosity obtained at the National Bureau of Standards.

\section{OSMOTIC-PRESSURE MEASUREMENTS}

The osmotic-pressure values for all the fractions, except the one of lowest molecular weight, were determined by the dynamic method of Fuoss and Mead [6]. The denitrated cellulose nitrate membranes recommended by these authors were used. The measurements were made at room temperature (approximately $28^{\circ}$ C.). The cell was placed in a box insulated with cotton waste, and the entire assembly was then covered with a wooden hood to minimize drifts caused by changes in temperature. Measurements of the osmotic pressures were made by means of a cathetometer sighted through a window in the hood. It was found practical to use the same membrane for a series of measurements by using increasing concentrations of the same sample in successive measurements, as recommended by Fuoss and Mead [6]. The membrane was then rinsed thoroughly with acetone, soaked overnight in this solvent, and rinsed thoroughly again, all without removing the membrane from the cell. This treatment sufficed to remove adhering cellulose acetate, so that the membrane could be used again.

With the fraction of lowest molecular weight (15), and to a lesser extent with the starting material, appreciable diffusion of the solute through the denitrated cellulose nitrate membranes occurred. For these two samples, cellophane membranes, swollen with $\mathrm{NH}_{4} \mathrm{OH}$ according to the directions of Flory [2], were therefore used. These measurements were made by the static method in a constant-temperature room. Equilibrium was reached overnight, after which no appreciable change in osmotic pressure occurred for a period of several days.

As the osmotic pressure measurements were made at slightly different temperatures, the values of $\bar{M}_{n}$ were calculated as follows: The apparent value of $\bar{M}_{n}$ at each concentration (and corresponding temperature) was first calculated by using the van't Hoff relationship, and the value of $\vec{M}_{n}$ at zero concentration was then obtained algebraically, assuming that the apparent value of $\bar{M}_{n}$ is a linear function of concentration.

\footnotetext{
4 Failure to apply kinetic energy corrections leads to errors of several percent in the values of the intrinsic viscosities of the fractions of higher molecular weight.
} 


\section{RESULTS AND DISCUSSION}

The results of the viscosity measurements are presented in table 1 and shown graphically in figure 1. In this figure the values of $\eta_{s p} / c$ are plotted on a logarithmic scale. When this procedure is followed, the results fall on straight lines suitable for extrapolation to zero concentration for obtaining the intrinsic viscosity. (When

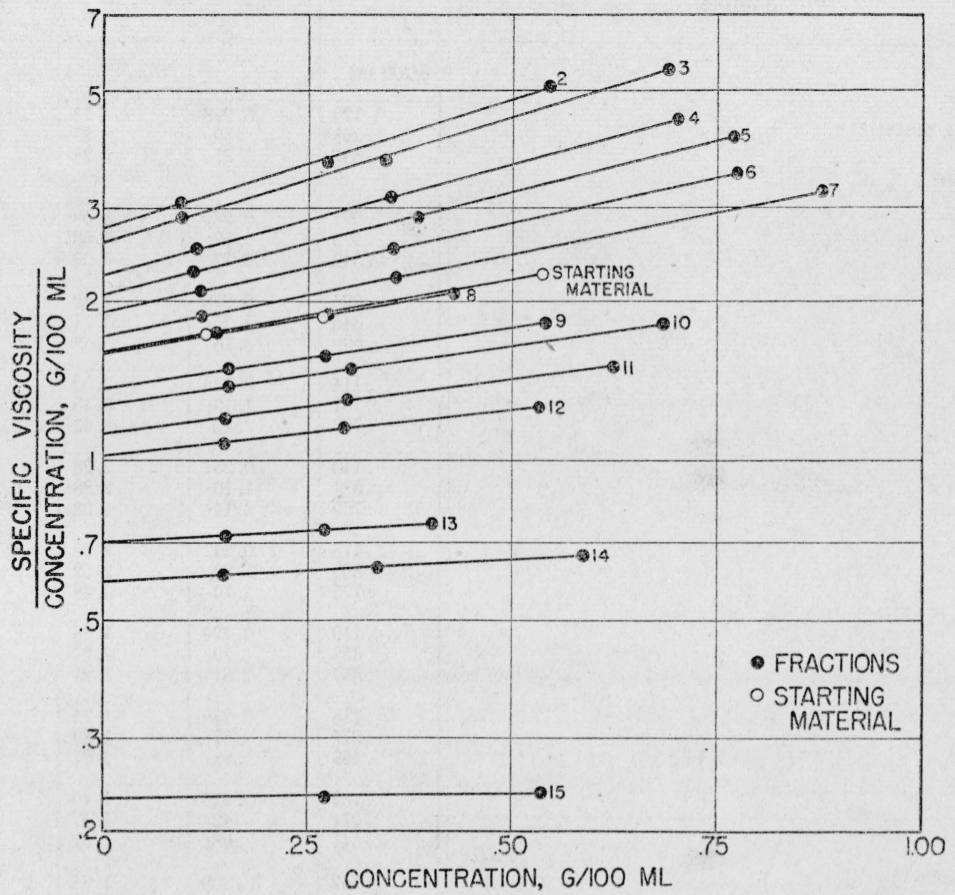

FIGURE 1.-Viscosity-concentration relationship in acetone solutions for cellulose acetate samples.

The samples are numbered in the order of their molecular weights to conform with their designations in a previous publication [4]. The lowest number represents the sample of highest molecular weight.

the values of $\eta_{s p} / c$ and $c$ are both plotted on a linear scale, the results do not fall on straight lines except at very low concentrations, where the experimental errors are largest. The use of the semilogarithmic plot gives weight to the more precisely determined values obtained in the range of higher concentrations).

The result of the viscosity measurements conform quite closely to Martin's equation [7]:

$$
\log \frac{\eta_{s p}}{C}=\log [\eta]+k[\eta] C
$$

in which $C$ is the concentration, ${ }^{5}$ and $k$ is a constant characteristic of a given polymeric series in a given solvent. The values of $[\eta]$ given

${ }^{5}$ It should be noted that the concentration is expressed in $\mathrm{g} / 100 \mathrm{ml}$ of solution in the data presented here. whereas it is given in weight-percent in reference [7]. 
in table 1 were obtained by algebraic extrapolation, using the method of least squares.

TABLE 1.-Viscosities of cellulose acetate samples in acetone solutions at $25^{\circ} C$

iThe samples are numbered in the order of their molecular weights to conform with their designations in a previous publication [4]. The lowest number represents the sample of highest molecular weight.]

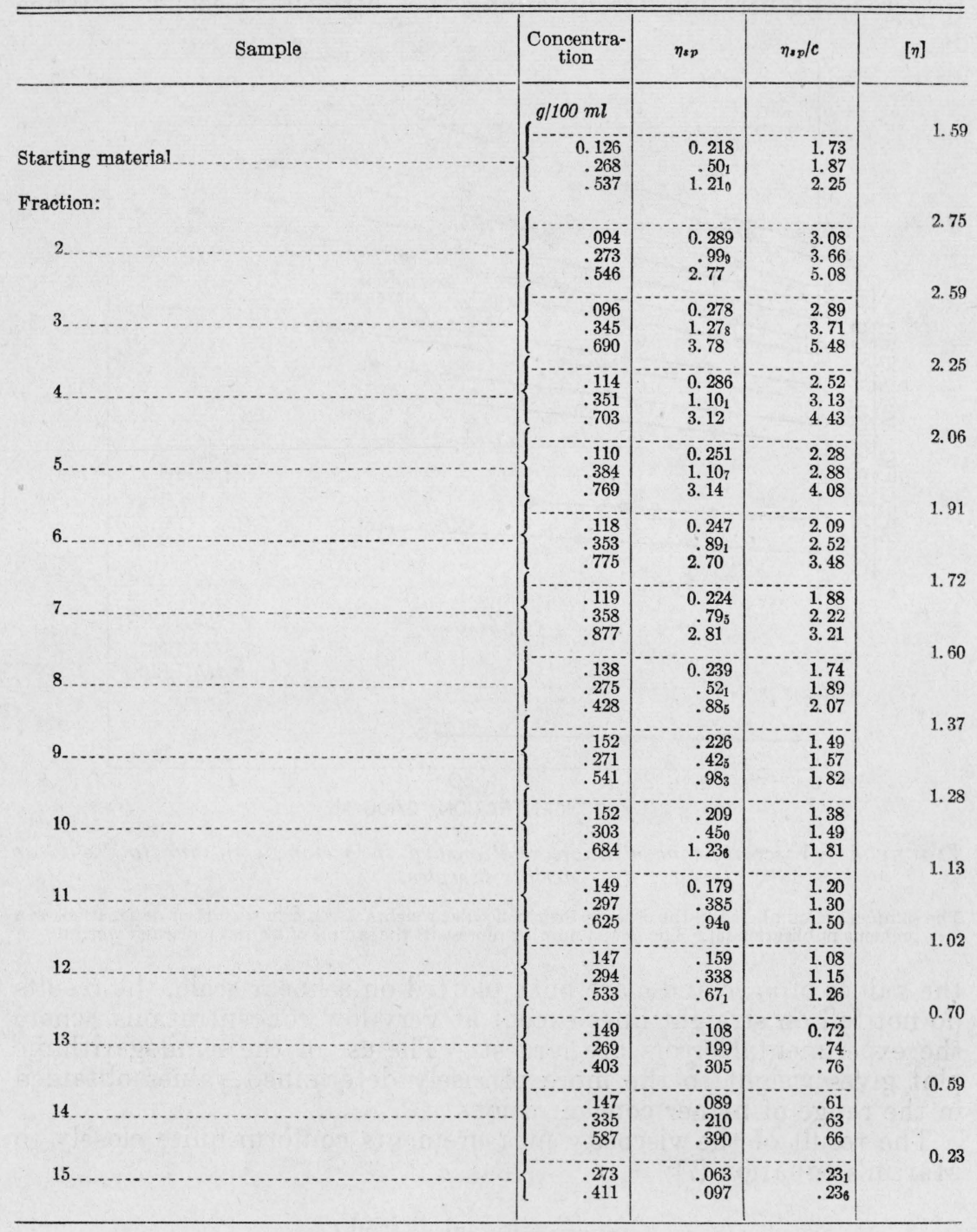

The results of the osmotic-pressure measurements are given in table 2. Since it has been shown that a plot of the reduced osmotic pressure $(\pi / c)$ against $c$ gives straight lines for samples of cellulose acetate in acetone [8], the osmotic-pressure values were determined at only two concentrations for most of the samples. The slopes of the lines obtained by plotting $\pi / c$ against $c$ are very nearly identical for 
all of the samples except the two fractions of lowest molecular weight (14 and 15), which give larger slopes. ${ }^{6}$

Figure 2 shows the relationship between the intrinsic viscosities and number-average molecular weights of the acetate fractions. The results appear to fall on a straight line passing through the origin, although the points for the two fractions of highest molecular weight appear to deviate somewhat from a line drawn through the remaining data. This deviation may be real, which would suggest that at higher values of molecular weight, the value of $[\eta]$ may increase less rapidly than $\bar{M}_{n}$ (i. e., the value of $a$ is less than unity in the equation $\left.[\eta]=K M^{a}\right)$. Results of this type have been obtained by Gralen and Svedberg for cellulose in cuprammonium [3]. It should be noted, however, that these fractions cover the usual molecular-weight range of commercial cellulose acetates. If the data are treated as though they conform with the relationship $[\eta]=K M^{a}$, a value for $a$ of 1.03 is

TABLE 2.-Osmotic pressures of cellulose acetate samples in acetone solutions

\begin{tabular}{|c|c|c|c|c|c|}
\hline Sample & $\begin{array}{l}\text { Concen- } \\
\text { tration }\end{array}$ & $\begin{array}{l}\text { Osmotic } \\
\text { pressure }\end{array}$ & $\begin{array}{l}\text { Tempera- } \\
\text { ture }\end{array}$ & Apparent & $\bar{M}_{n}$ \\
\hline & $\mathrm{g} / 100 \mathrm{ml}$ & cm acetone & ${ }^{\circ} \mathrm{C}$ & & \multirow{4}{*}{42,000} \\
\hline & 0.240 & & & 40,000 & \\
\hline Starting material & .449 & 3. 71 & 26 & 39,000 & \\
\hline & $\begin{array}{l}.837 \\
.899\end{array}$ & $\begin{array}{r}7.19 \\
8.03\end{array}$ & $\begin{array}{l}21 \\
26\end{array}$ & $\begin{array}{l}37,000 \\
36,000\end{array}$ & \\
\hline \multirow{2}{*}{$\begin{array}{r}\text { Fraction: } \\
2\end{array}$} & & & & & \multirow[t]{2}{*}{130,000} \\
\hline & $\begin{array}{l}.259 \\
.547\end{array}$ & $\begin{array}{l}0.67 \\
1.47\end{array}$ & $\begin{array}{l}26 \\
24\end{array}$ & $\begin{array}{l}126,000 \\
121,000\end{array}$ & \\
\hline 3. & .345 & 1. 10 & 28 & 102,000 & \multirow{2}{*}{110,000} \\
\hline & & & & & \\
\hline \multirow[t]{2}{*}{4} & .351 & 1. 37 & 27 & 84,000 & \multirow{2}{*}{86,000} \\
\hline & .703 & 2.83 & 27 & 81,000 & \\
\hline \multirow[t]{2}{*}{5.} & $\begin{array}{l}.384 \\
.769\end{array}$ & $\begin{array}{l}1.71 \\
3.59\end{array}$ & $\begin{array}{l}30 \\
30\end{array}$ & 74,000 & 78,000 \\
\hline & & & & & \multirow[t]{2}{*}{76,000} \\
\hline $6 \ldots$ & $\begin{array}{l}.388 \\
.775\end{array}$ & $\begin{array}{l}1.82 \\
3.98\end{array}$ & $\begin{array}{l}30 \\
31\end{array}$ & $\begin{array}{l}70,000 \\
64,000\end{array}$ & \\
\hline \multirow[t]{2}{*}{$7 \ldots$} & .439 & 2. 49 & 32 & 59,000 & \multirow{4}{*}{$\begin{array}{l}62,000 \\
61,000\end{array}$} \\
\hline & .877 & 5.33 & 33 & 55,000 & \\
\hline \multirow[t]{2}{*}{8.} & .428 & 2. 44 & 24 & 57,000 & \\
\hline & .855 & & 25 & 53,000 & \\
\hline 9. & .136 & 0.85 & 28 & 52,000 & \multirow{2}{*}{53,000} \\
\hline & .182 & 1.15 & 28 & 52,000 & \\
\hline & .28 & & 00 & 01,000 & \multirow[t]{2}{*}{48,000} \\
\hline $10 .$. & $\begin{array}{l}.342 \\
.684\end{array}$ & $\begin{array}{l}2.42 \\
5.14\end{array}$ & 24 & $\begin{array}{l}46,000 \\
43,000\end{array}$ & \\
\hline \multirow[t]{2}{*}{$11 \ldots$} & .312 & 2. 59 & 30 & 40,000 & \multirow{2}{*}{$\begin{array}{r}42,000 \\
34,000\end{array}$} \\
\hline & & 5. 44 & 31 & 38,000 & \\
\hline $12 \ldots$ & .266 & 2.68 & 30 & 33,000 & \multirow{3}{*}{33,000} \\
\hline & & & & & \\
\hline $13 .$. & .135 & 1. 34 & 30 & 33,000 & \\
\hline \multirow{2}{*}{14} & 168 & 2.41 & 25 & 23,000 & \multirow[t]{2}{*}{24,000} \\
\hline & .335 & 5.15 & 26 & 21,000 & \\
\hline \multirow[t]{2}{*}{15.} & .146 & 4. 52 & 25 & 10,400 & \multirow{2}{*}{11,000} \\
\hline & .291 & 9.75 & 25 & 9,700 & \\
\hline
\end{tabular}

${ }^{6}$ Fraction 15 diffused through the denitrated cellulose nitrate membranes of Fuoss and Mead [6]. When measurements were made by the dynamic method with these membranes, and the results were extrapolated back to zero time, the apparent value of $\bar{M}_{n}$ for fraction 15 was 16,000 . The value of $\bar{M}_{n}$ when the less permeable swollen cellophane membranes were used was 11,000 (table 2). 


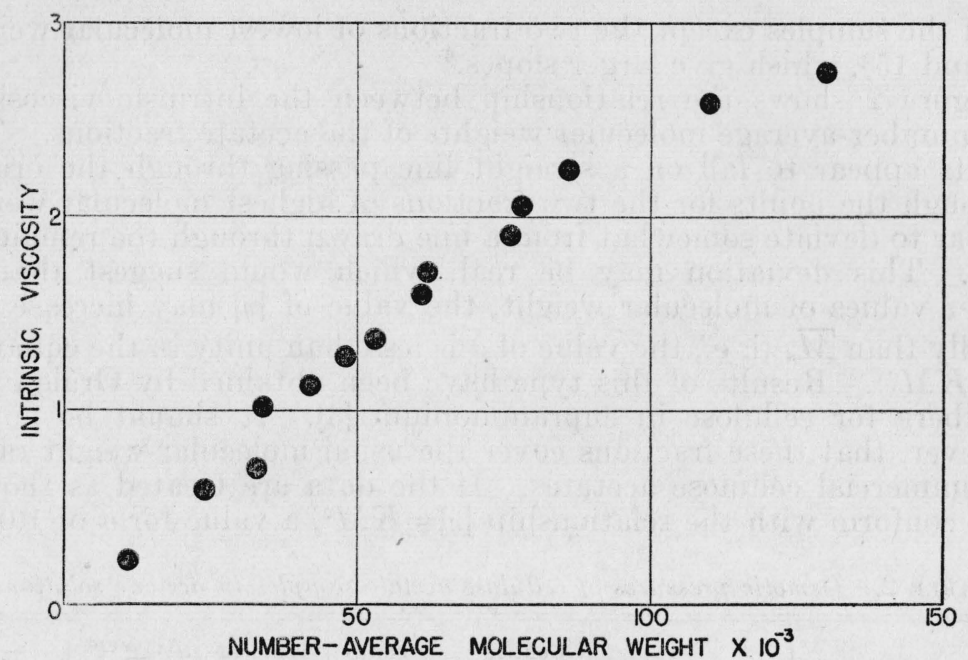

FIGURE 2.-Relationship between intrinsic viscosity and osmotically estimated molecular weight for cellulose acetate fractions.

obtained by the method of least squares. It should be noted that the value of $a$ is very sensitive to the results obtained for the fractions of lower molecular weight. Moderately small errors in the results for these fractions might change the value for $a$ appreciably.

From the best straight line drawn through the points in figure 2, the average relationship $\overline{D P}_{n}=150[\eta]^{7}$ (where $\overline{D P}_{n}$ is the numberaverage degree of polymerization) is obtained. ${ }^{8}$ The corresponding result obtained by Staudinger, who also used osmotic-pressure measurements to calibrate his viscosity method, is $\overrightarrow{D P}_{n}=110[\eta]^{7}[1]$. Kraemer measured the molecular weights of a series of secondary cellulose acetates by sedimentation equilibrium in the ultracentrifuge, and obtained the relationship $\overline{D P}_{w}=230[\eta]$ (where $\overline{D P}_{w}$ is the weightaverage degree of polymerization) [9]. These results suggest that the cellulose acetate fractions used in this study are more homogeneous than those used by Staudinger, but that they are not sufficiently homogeneous so that their weight- and number-average $D P^{\prime}$ 's are equal. This is shown by the results in table 3 .

Table 3 lists the number-average $D P$ 's of the fractions and starting material as obtained from the osmotic-pressure measurements in column 2. Column 3 lists the intrinsic viscosities, and column 4 the product $230[\eta]$, which according to Kraemer's results should approximate $\overline{D P}_{w}$. Since the ratio $D P_{w} / D P_{n}$ is unity for a perfectly homogeneous polymer, and increases with the heterogeneity with respect to molecular size, the value of the ratio may be taken as a measure of this heterogeneity. ${ }^{9}$ The values of this ratio for the

7 It should be noted that this relationship holds only for fractions of this particular degree of homogeneity. Viscosity results properly should be related to weight-average or viscosity-average molecular weights, rather than to number-average values. No estimate of $\overline{D P_{n}}$ can be obtained by viscosity measurements made on an unfractionated sample, or a fractionated sample of unknown degree of homogeneity.

8 The weight per glucose residue of cellulose acetate of this degree of acetylation is 260 [4].

- Because of the uncertainty involved in applying Kraemer's constant to these samples, the ratios of $\overline{D P}_{w} / \overrightarrow{D P}_{n}$ should not be taken as absolute values. Measurements of $\overline{D P}_{w}$ for several of these samples by ultracentrifugal and light-scattering methods are in progress. 
TABLE 3.-Comparative $D P_{n}$ 's and intrinsic viscosity results for cellulose acetate samples

\begin{tabular}{|c|c|c|c|c|}
\hline Sample & $\overrightarrow{D P}_{n}$ & {$[\eta]$} & $230[\eta]$ & $\frac{230[\eta]}{\overparen{D P}_{n}}$ \\
\hline Starting material & 160 & 1. 59 & 366 & 2.3 \\
\hline $\begin{array}{l}\text { Fraction: } \\
2\end{array}$ & $\begin{array}{l}502 \\
422 \\
331 \\
298\end{array}$ & $\begin{array}{l}2.75 \\
2.59 \\
2.25 \\
2.06\end{array}$ & $\begin{array}{l}633 \\
596 \\
518 \\
474\end{array}$ & $\begin{array}{l}1.3 \\
1.4 \\
1.6 \\
1.6\end{array}$ \\
\hline 6 10 & $\begin{array}{l}291 \\
240 \\
234 \\
204 \\
186\end{array}$ & $\begin{array}{l}\text { 1. } 91 \\
\text { 1. } 72 \\
\text { 1. } 60 \\
\text { 1. } 37 \\
\text { 1. } 28\end{array}$ & $\begin{array}{l}439 \\
396 \\
368 \\
315 \\
294\end{array}$ & $\begin{array}{l}\text { 1. } 5 \\
\text { 1. } 7 \\
\text { 1. } 6 \\
\text { 1. } 5 \\
\text { 1. } 6\end{array}$ \\
\hline 112 & $\begin{array}{r}160 \\
131 \\
127 \\
92 \\
43\end{array}$ & $\begin{array}{r}1.13 \\
1.02 \\
0.70 \\
.59 \\
.23\end{array}$ & $\begin{array}{r}260 \\
234 \\
161 \\
136 \\
53\end{array}$ & $\begin{array}{l}1.6 \\
1.8 \\
1.3 \\
1.5 \\
1.2\end{array}$ \\
\hline
\end{tabular}

several samples are shown in column 5 . The starting material, with a ratio of $\overline{D P}_{w} / \overline{D P}_{n}$ of 2.3 , is manifestly less homogeneous than any of the fractions, the ratios for which range between 1.2 and 1.8. The fact that the lowest value obtained for this ratio is slightly higher than unity is entirely consistent with Kraemer's results. However, the heterogeneity of all of the samples may be somewhat different from that indicated by these ratios, since the value of Kraemer's constant is subject to some uncertainty [9]. The results indicate that the samples have not all been fractionated to the same degree.

From the values in table 3 and the yields of the fractions, summated values of $[\eta]$ and $\overrightarrow{D P}_{n}$ can be calculated. These calculated values are $[\eta]=1.50$ and $\overline{D P}_{n}=175$, compared with experimental values for the starting material of 1.59 and 160 , respectively. Since the results do not include fraction 1 , which was not completely soluble in acetone, and as a certain amount of loss is inevitable in a long fractionation procedure, the results represent reasonably good agreement between the calculated and observed values.

\section{REFERENCES}

[1] H. Staudinger, Die Hochmolekularen Organischen Verbindungen (J. Springer, Berlin, 1932).

[2] P. J. Flory, J. Am. Chem. Soc. 65, 372 (1943).

[3] N. Gralen and Th. Svedberg, Nature 152, 625 (1943).

[4] A. M. Sookne, H. A. Rutherford, H. Mark, and M. Harris, J. Research NBS 29, 123 (1942) RP1490.

[5] E. C. Bingham, Fluidity and Plasticity, p. 17 (McGraw-Hill Book Co., New York, N. Y., 1922).

[6] R. M. Fuoss and D. J. Mead, J. Phys. Chem. 47, 59 (1943).

[7] E. Ott, Cellulose and Cellulose Derivatives, p. 966 (Interseience Publishers, New York, N. Y., 1943).

[8] A. Dobry, Bul. Soc. Chim. [5] 2, 1882 (1935).

[9] E. O. Kraemer, Ind. Eng. Chem. 30, 1200 (1938).

Washington, December 14, 1944. 